IRA-International Journal of Technology \& Engineering ISSN 2455-4480

Proceedings of the

International Conference on Science \& Engineering for Sustainable Development (2017)

Pg. no.226-236

Published by: Institute of Research Advances https://research-advances.org/index.php/IRAJTE

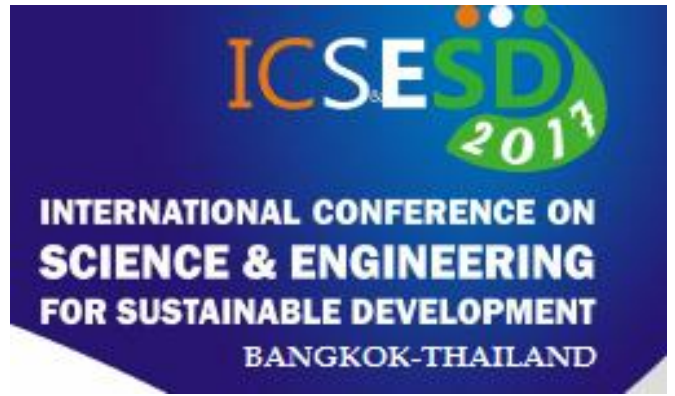

\title{
Computer Aided Design and Analysis of Tapping Tool with Diametrical flexibility
}

\author{
Satish G. Bahale*1 ${ }^{*}$ Amit Shende ${ }^{2}$ \\ ${ }^{1}$ Proessor, Mechanical Department, PRMIT\&R Badnera, India. \\ ${ }^{2} \mathrm{ME}$ (CAD/ CAM),Mechanical Department, PRMIT\&R Badnera, India.
}

Type of Review: Originality Check \& Peer Review under the responsibility of the Scientific Committee of the Conference and The Institution of Engineers (India). DOI: http://dx.doi.org/10.21013/jte.ICSESD201722

\section{How to cite this paper:}

Bahale, S., Shende, A. (2017). Computer Aided Design and Analysis of Tapping Tool with Diametrical flexibility. Proceedings of the International Conference on Science \& Engineering for Sustainable Development (2017), 226-236. doi: http://dx.doi.org/10.21013/ite.ICSESD201722

(C) International Conference on Science \& Engineering for Sustainable Development\& The Institution of Engineers (India).

\section{(cc) BY-NC}

This work is licensed under a Creative Commons Attribution-Non Commercial 4.0 International License subject to proper citation to the publication source of the work.

Disclaimer: The conference papers as published by the Institute of Research Advances (IRA) are the views and opinions of their respective authors and are not the views or opinions of the IRA. The IRA disclaims of any harm or loss caused due to the published content to any party. 


\section{ABSTRACT}

Tapping operation which refers to production of internal threads forms an integral part of any machine shop and it is intended to provide semi permanent fastening to the components of product so as to lend themselves for repairs and replacements. Though various methods of internal threading are available such as internal threading by milling, grinding or forming but internal threading by metal cutting which employs a tapping tool is indeed the mostly used for products where accuracy forms the base of evaluation. Last few decades have seen the growth of automobile industries and has resulted in development of its allied operations of which tapping is one of the crucial operation performed. The conventional tapping operation which surely involves rotating the tool and feeding past the pre drilled hole to create the contours called as internal threads and this is followed by withdrawal of tapping tool by reversing it with aid of rotational energy. The present paper attempts to design and analyze a tapping tool which will have no requirement of reversing of tool at the end of cutting operation which is essentially done by changing the design of conventional solid tap. The solid tapping tool is divided into two parts along the longitudinal axis and a mechanism is prompted to give the two parts actuation which would shrink at the end of cutting operation to be dragged out of hole without damaging the machined surface and providing the diametrical flexibility to engulf other diameters to be machined. This tapping tool with diametrical flexibility is designed in CAD tool named as CATIA V5 and efficiently analyzed by using FEA technique which is the working phenomenon for ANSYS.

Keywords: Tapping Tool, Analysis, FEA

\section{Introduction}

Generation of internal threads by metal cutting is generally done by employing tapping tool of the form which is similar to form of thread to be generated. The tapping tool is provided the necessary torque for cutting by using lathe machine, drilling machine and CNC turning centres which provide the necessary cutting action by the edges of tapping during feeding of tapping tool across the pre drilled hole. The removal of tapping tool is assured by anticlockwise rotation of spindle which holds the tool and considerably accounts for energy and time for operation of tapping. In this project the conventional tapping tool is divided into two parts which retain cutting edges two on each side so as to shrink in size or collapse at the end of cutting of internal threads which would facilitate easy withdrawal of tapping tool without reversing the same. Computers employing microelectronics technology are called for aiding the geometric modeling of system which would provide the actuation in terms of diametrical flexibility to the two parts of tapping tool employed for cutting. This tool in two parts is subjected to torque due to cutting action and this analyzed under the view of structural analysis which has become an indispensible part of evaluation system used for validation of design .Geometrically modeled tapping tool in CATIA V5 is subjected to tapping torque acting on it and the shear stress results are calculated by FEA software named as ANSYS which are compared with the shear stress acting on the solid tap employed in conventional tapping to provide a platform for evaluation and validation of design. 


\section{Conventional Tapping On Drilling Machines}

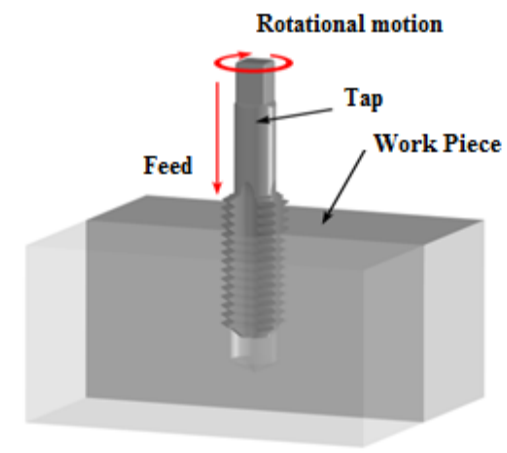

Fig.no.1. Conventional Tapping on Drilling machine.

Tapping operation is carried on drilling machine conventionally by holding the tap in the spindle which while rotating in horizontal plane moves vertically in downward direction past the work piece to generate internal threads. Depending upon the material of work piece the torque is acting on the tapping tool which is resisting in nature and has the effect of damaging out the cutting edges of tapping tool. Tapping tool is available in form of three geometries namely the plug tap , taper tap and bottom tap among which bottom tap is used to tap the blind holes by machine tapping. During each tapping operation the tap is to be reversed for its removal from machined surface and for various diameters of holes various tap are employed which requires considerable amount of time in form of installation new tap size. Moreover tapping operation is complex in nature due to the fact that the tool it employs is brittle in nature which leads to tap breakage in the pre drilled hole and thus it poses a serious problem as tapping is the last operation mainly carried out on product to be assembled and thus any error would render the previous work done as wastage and lead to failure of product. To overcome this problems the conventional design of tapping tool is subjected to a change of diametrical flexibility which owes its function to the feature of dividing the tool into two parts and actuating the same by aid of actuation member fastened by spring and actuation done through lead screw for efficient movement of tapping bits to set the diameter.

\section{Research Problem Definition}

The present work provides an insight of the mechanism involving the actuation of tapping tool with diametrical flexibility by the help of lead screw arrangement and this is studied by taking into consideration the tree tap sizes of M24, M26 and M28 which are successively varied to perform cutting operation on work piece of aluminium. The torque ratings for the tap with collapsibility are to be compared with the solid tap torque rating so as the get the view of cutting in terms of tap failure.

\section{Methodology}

1] To induce the feature of collapsibility in the working of tap by providing it the diametrical flexibility.

2] To vary the diameter of tap in certain range to provide different tap diameter with same tap.

3] To design an adapter enclosing the arrangement of diametrical flexibility to provide the same.

4] To regain the original diameter after collapsing the tap at the end of cutting operation. 
5] To analyze the torque acting on tap at diameter of $24 \mathrm{~mm}, 26 \mathrm{~mm}$ and $28 \mathrm{~mm}$ to compare them with the standard torque requirement of solid taps.

\section{Geometric Modelling In CATIA V5}

1] The actuation system for two bits of tapping tool are geometrically modeled by invoking CATIA V5 software. The number of components are each modeled using part modeling module of CATIA V5 and then assembled by subjecting the various components to bottom- up assembling method employed in assembly module of software. Various components modeled and subsequently assembled as final product can be illustrated here

2] The first component to be modeled is in shape of disc of thickness $8 \mathrm{~mm}$ and diameter of $70 \mathrm{~mm}$ with a diametrical slot of $54 \mathrm{~mm} \times 10 \mathrm{~mm}$ to support the member to hold the bits of tap .

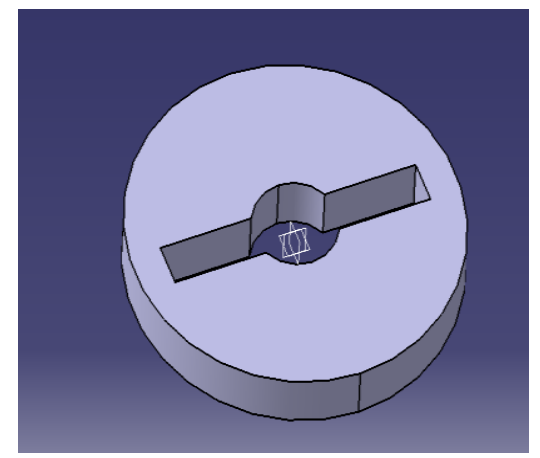

Fig.no.2. Geometric Modeling of Disc with slot

3] The next part modeling deals with geometrically designing the subassembly employed for actuation by tapping bits assembly. This subassembly consist of various components such as block for holding the tap bits, actuation member, spring, handle, tap bits and lead screw. The block for holding the tapping bits and actuation member are modeled as single component as they do not have any relative motion against each other and consequently assembled with other components which are individually modeled to give the following subassembly of system.

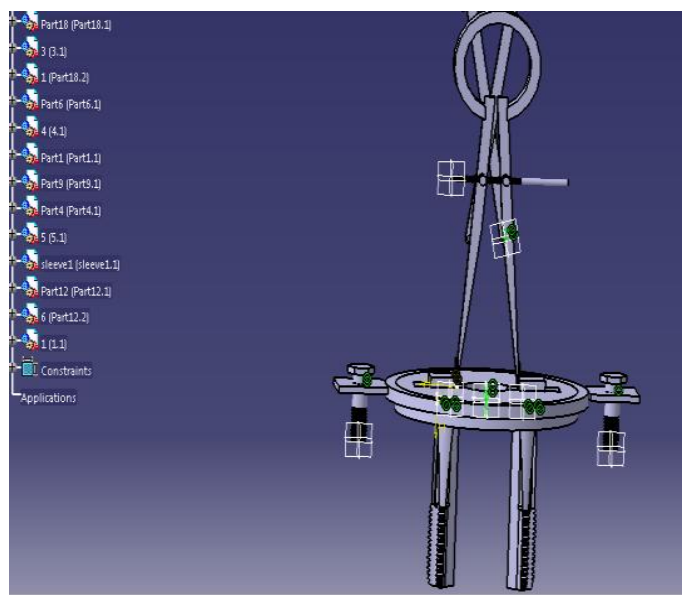

Fig.no.3. Geometric Modeling of Subassembly for Actuation of Tapping Bits.

4] The last component is a cylindrical shaped pipe of internal diameter $70 \mathrm{~mm}$ and thickness of $5 \mathrm{~mm}$ 
placed on the disc having slot and bolted to the previous subassembly by nut and bolt fastening. The pipe is of length $170 \mathrm{~mm}$ and contains a disc bolted at its upper end. The upper disc is bearing a sleeve possessing a Morse taper of 3 to be push fitted to the drilling machine having spindle rotating in horizontal plane.

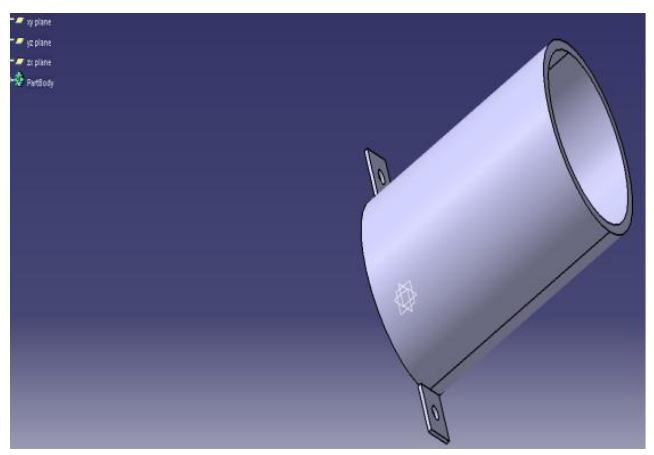

Fig.no.4. Geometric Modeling of Pipe

5] All the components and subassemblies modeled previously are assembled as single product to provide the design of tapping tool with diametrical flexibility. The constraint provided are geometrical constraint which are used to define the relation of various components with each other as shown below.

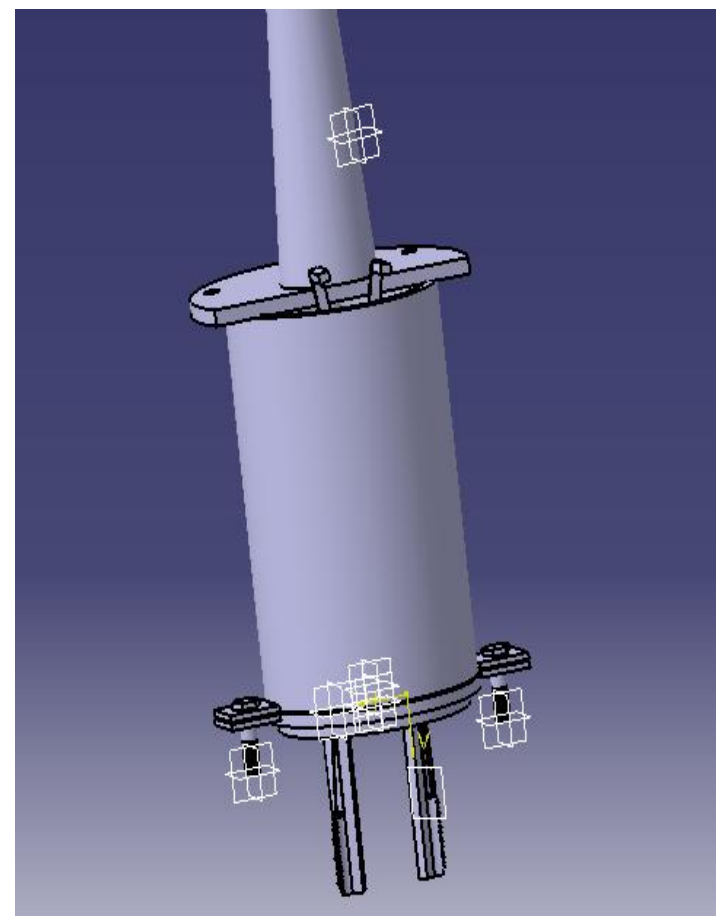

Fig.no.5. Assembly of the system 


\section{Working of System}

The system for diametrical flexibility with is various components is modeled and assembled according to their geometric relations with each other in a CAD tool. The section view of assembly of system shows the various components. It can be seen from the view that the actuation member holding the tapping bits are connected through a circular spring and the holding block for tapping bits rests on the circular disc of slot having diameter of $70 \mathrm{~mm}$. The lead screw provides the actuation force through the movement of spindle to contract or expand the tapping bits in diametrically inward and outward direction. The lead screw is fixed to one of actuation member on left side and when force acts on left actuation member it gives equal and opposite reaction to actuation member on right side through spring and thus the alignment of both the actuation member and consequently both the tapping bits remain same from central axis and variation occurs in diameter which allows it to contract for collapsibility of tap and to engulf the various sizes as they are M24, M26 and M28 in this work. The assembly is push fitted in the spindle of drilling machine and rotated past the pre drilled holed to create internal threads and at the completion of cutting operation the handle is pressed which compress the bits in radially inward direction to collapse the size of bit and withdraw the tool from the hole without reversing.

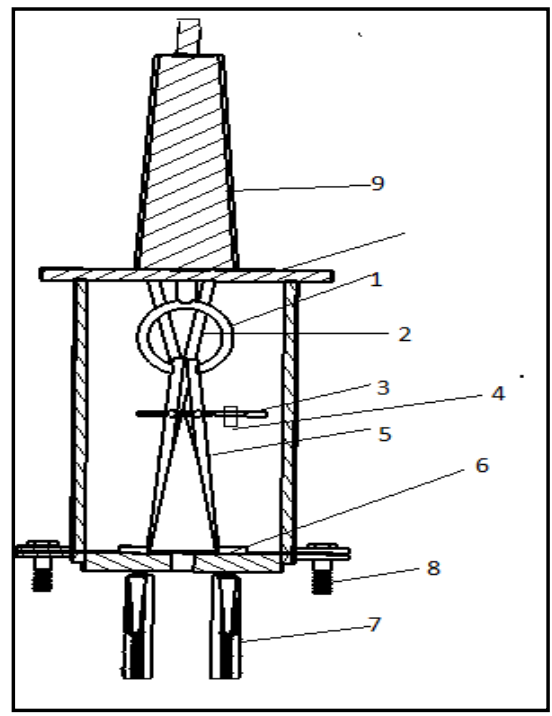

Fig.no.6. Section View of System

1-Spring 2- Handle

3- Lead screw 4- Spindle for lead screw

5- Actuating member 6- Block for holding the tap

7- Collapsible Tap 8- Bolt

9- Sleeve 10- Disc

\section{Design Analysis Of System}

1] The adaptive design for diametrical flexibility of tapping tool proposed here can be analyzed with a view of torque acting on the tapping tool. The torque acting on tapping tool is dependent on the material of work piece, geometrical complexity of tap and alignment with the pre drilled hole. This torque is the result of resistance force acting tangentially to the teeth of tapping tool as shown in figure below and it results into breakage or chipping of the teeth of tapping tool which in turn disposes the tapping tool as waste material. 


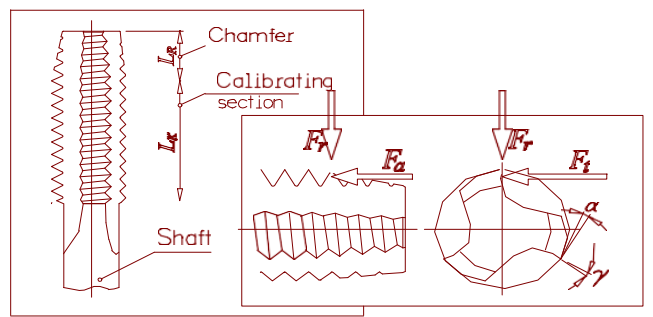

Fig.no.8. Forces acting on Tapping Tool

2] The solid tapping tool which is lacking the diametrical flexibility is subjected to torque which is calculated by an empirical relation which takes into account the diameter of hole to be tapped and the material of the work piece which is aluminium in this case. This machining conditions remains same for tapping tool with diametrical flexibility and thus the solid tap and tap with diametrical flexibility are subjected to same torque conditions but the results which is in terms of maximum principal stress is used to demarcate the design of two tools for validating the same. The experimental values of torque acting on solid tapping tool are given by the empirical relation provided by Taflet tool Co. which are used to calculate the shear stress acting on tapping tool of diameter $24 \mathrm{~mm}, 26 \mathrm{~mm}$ and $28 \mathrm{~mm}$.

\section{Torque $=0.0491 \times \mathrm{K} \times \mathrm{E} \times \mathrm{P}$}

Where $\mathrm{K}=$ coefficient of material to be machined which is equal to 0.4 for aluminium

$\mathrm{E}=$ Basic pitch diameter of tap hole

$\mathrm{P}=$ thread pitch of tap

$\frac{T}{J}=\frac{C \theta}{\mathbb{L}}=\frac{\pi}{x}$

Where, $\mathrm{T}=$ torque acting on member

$\mathrm{J}=$ Polar moment of inertia $=\frac{\pi}{\pi 2} \times d^{4}$

$\mathrm{C}=$ Modulus of rigidity, $\Theta=$ angle of twist $\mathrm{L}=$ length of member subjected to torsion

$\tau=$ shear stress $\mathrm{x}=$ distance of neutral axis from the point of application of load.

According to maximum principal stress theory the maximum principal stress is given by $\sigma_{1} \cdot \frac{\left(\sigma_{x}+\sigma_{2}\right)}{2} \cdot \sqrt{\frac{\left(\sigma_{1}-\sigma_{j}\right)^{2}}{4} \cdot \tau_{x y}^{2}}$

Here $\sigma \mathrm{x}=\sigma \mathrm{y}=0$ and $\tau \mathrm{xy}=$ shear stress due to moment

Table.no.1. Torque and Shear Stress on Solid Tapping Tool

\begin{tabular}{|r|l|l|}
\hline $\begin{array}{l}\text { TAP SIZE } \\
\text { IN MM }\end{array}$ & $\begin{array}{l}\text { TORQUE in N- } \\
\mathrm{m}\end{array}$ & $\begin{array}{l}\text { MAX } \\
\text { PRINCIPL } \\
\text { E STRESS } \\
\text { in N/mm }\end{array}$ \\
\hline 24 & $4.7068 \times 10^{-9}$ & 1.73 \\
\hline 26 & $5.09912 \times 10^{-9}$ & 1.477 \\
\hline 28 & $5.2952 \times 10^{-9}$ & 1.370 \\
\hline
\end{tabular}

3] The tapping tool with diametrical flexibility when subjected to torque is analyzed in FEA tool which is ANSYS and the results of shear stress are calculated by consecutively meshing the assembly of tap 
bits and subjecting it to given torque values calculated by using empirical relation. The shear stress results are shown in following figures below.

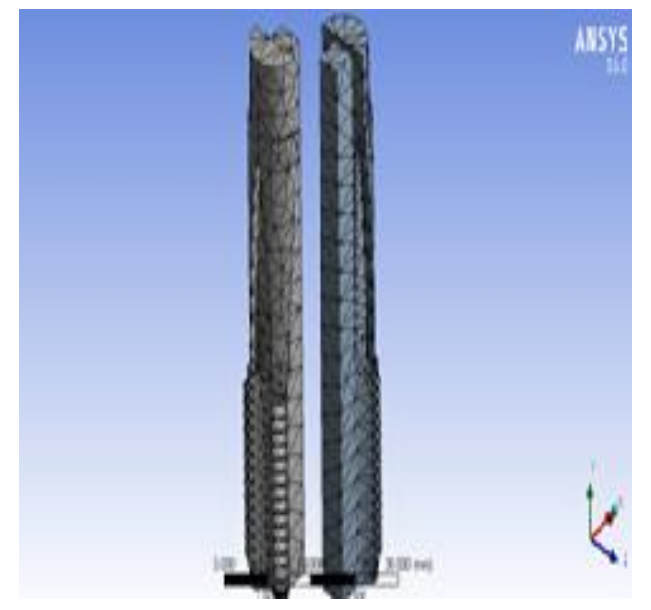

Fig.no.9 Meshing of Tapping tool with Daimetrical Flexibility

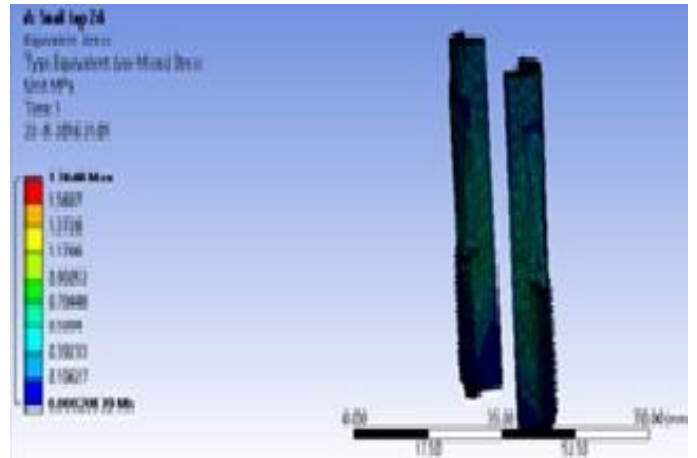

Fig.no.10 Nodal Solution of M24 Tapping Tool

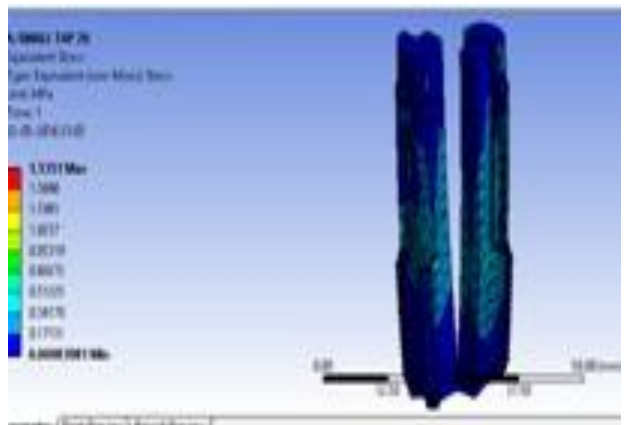

Fig.no.11 Nodal Solution of M26 Tapping tool 


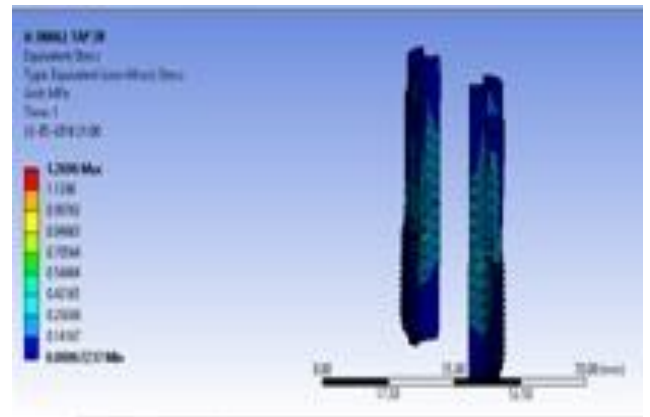

Fig.no.12 Nodal Solution of M28 Tapping tool

\section{Results And Comparison}

1] The process of designing and analyzing the system with relevant parameters of study is followed by inferences generated by evaluation process of the data obtained during the process of analysis The results calculated can be drawn on the lines of effect of torque which is shear stress in this case. The various input values which are same for both conditions are presented and the variation in the effect due to design variation in the system can be presented as follows. The Shear strength of HSS M2 Tool employed for metal cutting has the value of $100 \mathrm{~N} / \mathrm{mm}^{2}$. [11] The values of shear stress acting on tapping tool with diametrical flexibility are found to be lower than the shear strength of High Speed Steel employed for generation of internal threads and thus validates the design as safe.

Table.no.2. Torque on Solid Tapping Tool

\begin{tabular}{|l|l|l|l|}
\hline Property & \multicolumn{3}{|l|}{$\begin{array}{l}\text { Tapping tool with diametrical } \\
\text { flexibility }\end{array}$} \\
\hline & M24 & M26 & M28 \\
\hline $\begin{array}{l}\text { Tool } \\
\text { Material }\end{array}$ & HSS & HSS & HSS \\
\hline $\begin{array}{l}\text { Shear } \\
\text { strength of } \\
\text { HSS in N/ } \\
\text { mm2 }\end{array}$ & 100 & 100 & 100 \\
\hline $\begin{array}{l}\text { Work } \\
\text { material }\end{array}$ & Aluminium & $\begin{array}{l}\text { Aluminiu } \\
\text { m }\end{array}$ & Aluminium \\
\hline $\begin{array}{l}\text { Boundary } \\
\text { condition }\end{array}$ & $\begin{array}{l}\text { Fixed } \\
\text { support on } \\
\text { top }\end{array}$ & $\begin{array}{l}\text { Fixed } \\
\text { support on } \\
\text { top }\end{array}$ & $\begin{array}{l}\text { Fixed } \\
\text { support on } \\
\text { top }\end{array}$ \\
\hline $\begin{array}{l}\text { Torque on } \\
\text { tool (in N- } \\
\text { m) }\end{array}$ & 4.7068 & 5.09912 & 5.2952 \\
\hline $\begin{array}{l}\text { Maximum } \\
\text { principle } \\
\text { stress on } \\
\text { tap in N/ } \\
\text { mm2 }\end{array}$ & 1.768 & 1.5351 & 1.2696 \\
\hline
\end{tabular}


Table.no.3. Torque on Tapping Tool with diametrical flexibility

\begin{tabular}{|l|l|l|l|}
\hline Property & \multicolumn{3}{|c|}{ Solid Tapping tool } \\
\hline & M24 & M26 & M28 \\
\hline Tool Material & HSS & HSS & HSS \\
\hline $\begin{array}{l}\text { Shear } \\
\text { Strength of } \\
\begin{array}{l}\text { HSS in N/ } \\
\text { mm }^{2}\end{array}\end{array}$ & 100 & 100 & 100 \\
\hline $\begin{array}{l}\text { Work } \\
\text { material }\end{array}$ & $\begin{array}{l}\text { Aluminiu } \\
\text {-m }\end{array}$ & $\begin{array}{l}\text { Aluminiu } \\
\text { m }\end{array}$ & $\begin{array}{l}\text { Aluminiu } \\
\text { m }\end{array}$ \\
\hline $\begin{array}{l}\text { Boundary } \\
\text { condition }\end{array}$ & $\begin{array}{l}\text { Fixed } \\
\text { support } \\
\text { on top }\end{array}$ & $\begin{array}{l}\text { Fixed } \\
\text { support on } \\
\text { top }\end{array}$ & $\begin{array}{l}\text { Fixed } \\
\text { support on } \\
\text { top }\end{array}$ \\
\hline $\begin{array}{l}\text { Torque on } \\
\text { tool (in N- } \\
\text { mm) }\end{array}$ & 4.7068 & 5.09912 & 5.2952 \\
\hline $\begin{array}{l}\text { Maximum } \\
\text { principle } \\
\text { stress on tap } \\
\text { in N/mm }\end{array}$ & 1.73 & 1.477 & 1.370 \\
\hline
\end{tabular}

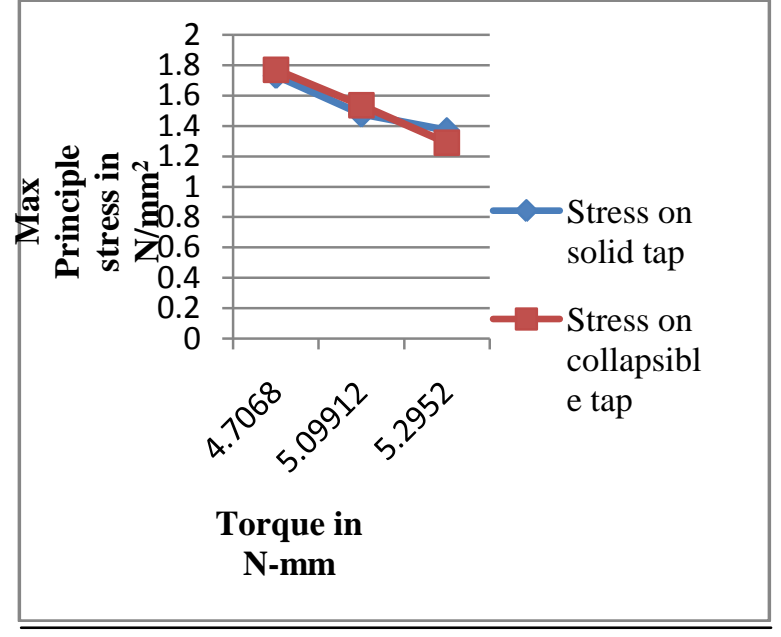

\section{Conclusion}

Thus it can be inferred that this paper projects a work to show that an adaptation in conventional design of tapping tool geometry can be employed to save the time of machining and energy involved in each operation of tapping by providing the diametrical flexibility to the tapping tool by mechanism of actuation modeled in CAD tool. The evaluation of tapping torque and relevant shear stress by using FEA technique and comparing it with the standard maximum principal stress acting on conventional tapping employing High Speed Steel shows that tapping tool with diametrical flexibility is achieving the saving in time of operation and energy and at the same time it is under the safe zone of maximum principal stress acting on it. Thus the mechanism can be efficiently applied for tapping operation 


\section{References}

[1] S. S. Patil, S. S. Pande and S. Somasundaram Some investigations on vibratory tapping process, International Journal of Machine Tools Manufacture, 27(.3), 1987, 343-350.

[2] E. D. Doyle and S. K. Dean, Effect of axial forces on dimensional accuracy during tapping International Journal of Machine Tool Design and Research, Pergamon press, Vol. 14, 1974, 325333.

[3] G. Lorenz, "on tapping torque and tap technology, Annals of the CIRP, CSIRO, Melbourne, Australia, 1980, pp. 1-4.

[4] De-Yuan Zhang and Ding Chang Chen, Relief face friction in vibration tapping, International Journal of Mechanical sciences, 40, (12), 1998, 1209-1222

[5] Tengyun Cao and John W. Sutherland, investigation of thread tapping load characteristics through mechanistic modeling and experimentation, International Journal of 42, 2002, 15271538.

[6] W. Li, D. Li and J. Ni, Diagnosis of tapping process using spindle motor current International Journal of machine Tools \& Manufacturing, ELSEVIER, 43, 2003, 73-79

[7] Armarego, E.J.A., Chen, M.N.P.: Predictive Cutting Models for Forces and Torque in Machine Tapping with Straight Flutes, Annals of the CIRP, Vol 51, No. 1, pp. 75-78, 2000

[8] Kokotović, B., Puzović, R., Tanović, Lj., Kalajdžić, M.: Model of thrust force and torque in tapping operations, Heavy Machinery-HM'05, Conference Proceedings, pp. A.63-A.66, Kraljevo, Serbia, 2005.

[9] Jovičić, M.: Process by cutting heavily machinablemetals and alloys, Faculty of MechanicalEngineering, University of Belgrade, Belgrade, 1992, (in Serbian).

[10] Oberg, E., Jones, F.D., Horton, H.L.: Machinery'sHandbook, 23rd Edition, Industrial Press Inc., NewYork, 1990

[11] E. Trent, "Cutting Tool Materials I : High Speed Steel," in Metal Cutting, fourth Edition, USA: B.H, 2000, pp.144-165 